\title{
Mechanical behaviour of pre-stressed spruce timber-timber 2.5-mm-step grooved connections under shearing tests
}

\author{
Stéphane Girardon ${ }^{1} \cdot$ Jean-François Bocquet ${ }^{2}$
}

\begin{abstract}
A smart shear connection system was tested in order to be used in manufactured elements of a lattice of wooden slats and a cross offset. This type of floor element can present advantages both in terms of weight and suitable insulating filler (Adalberth et al. 2001; Kawasaki and Kawai 2006; Kermani and Hairstans 2006; Dodoo et al. 2014). This connection is made to provide a substitute for a glue connection. The shear connection proposed is made by double-sided grooving timber interfaces to form a cross section. A specifically designed test assembly was constructed to measure and guarantee homogeneous contact pressure in interface test specimens. Shear test results are presented and compared in terms of capacity and stiffness with glue connections. The principal conclusions are as follows: the allowable shearing resistance of the grooved timber-timber joints can approximately reach the resistance of glued connections. The stiffness of the joints is improved by increasing the pre-stress applied for holding contact in the assembly. The grooved timber-to-timber joints exhibit non-linear behaviour which dominates the behaviour of the whole system. Therefore, the behaviour of a unit connection must be determined to obtain the mean load-carrying capacity and stiffness of a system with grooved connections.
\end{abstract}

Stéphane Girardon

Stephane.Girardon@ensam.eu

1 LaBoMaP, Centre Arts et Métiers ParisTech de Cluny, Rue Porte de Paris, 71250 Cluny, France

2 Lermab, 27 rue Philippe SÉGUIN, CS 60036, 88026 Épinal Cedex, France

\section{Introduction}

The focus of this study is the evaluation of a connection system for multilayer prefabricated elements used for floors and walls in timber hollow-box structures. These elements are used as a lightweight solution to provide high bending stiffness. Each slab is made up of alternating rows of wood and insulation. The number of slabs can be adjusted to use the right amount of wood according to target performance in terms of resistance, deflection, thermal or sound insulation. This system can offer high-performing building solutions (Resch 2009) and is environmentally friendly in that it increases recyclability and sustainability (Aye et al. 2012). In order to obtain a high bending stiffness, the connection system between the timber members must transfer shear forces effectively and must have high slip modulus and load capacity.

Structural glue or screw-gluing techniques are common and effective ways to connect element interfaces (Crocetti et al. 2010; Zarnani and Quenneville 2014). An example is shown in Fig. 1. However, the gluing process can be demanding in terms of equipment, preparation, and quality control. The assembly time of grooved multilayer elements can be reduced compared with gluing techniques as there is no need for curing. The grooved elements can be integrated into a fully automated production line. Therefore, shear connections made with grooves must be secured against separation forces by using fasteners like screws.

As a first step in development, this study presents an evaluation of the performance of grooves as shear connectors without holding fasteners. An experimental study is proposed in order to understand the behaviour of such connections and how it is affected by holding stress. Results of shear tests on different configurations are discussed. 


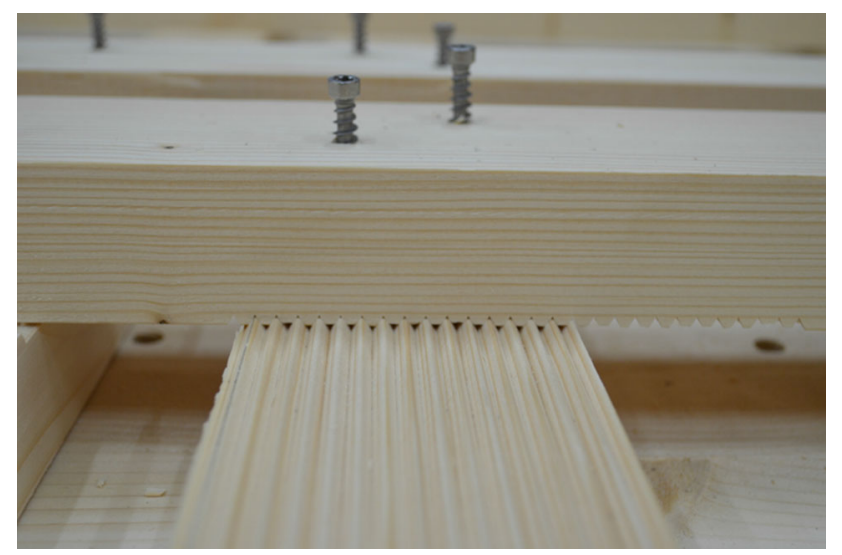

Fig. 1 Example of grooved connection which is maintained by 2 wood screws (Girardon 2014)

\section{Materials and methods}

An experimental shear test program was carried out at the laboratory of LERMaB (Laboratoire d'étude et de recherche sur le matériau bois) in France. Thirty five shear tests with three different pre-stressing conditions were performed.

\subsection{Shear specimen}

Test specimens were composed of two parts which are grooved $(100 \times 100 \mathrm{~mm})$ on one side of the surface. The grooves are oriented along the slope of the grain to transmit force perpendicular to the slope of the grain. A first step is to characterise a simple interface with a unidirectional transmitting strength. This is to avoid complex interactions which could be difficult to evaluate without a basic understanding of elementary phenomena.

A saw-tooth shape was chosen over a square-tooth shape from a mechanical behaviour viewpoint, as the tension value for rupture of the cross section and the shear failure value are very weak. Indeed, a saw-tooth shape permits transmitting strength both by shearing and compression while a square-tooth shape transmits only shear loads (see Fig. 2).

Therefore, a saw-tooth-shaped interface was studied with a tooth pitch of $2.5 \mathrm{~mm}$ and a $60^{\circ}$ tooth angle. Geometry of the tooth is presented in Fig. 3.

The test specimens were made from 4 French spruce (Picea abies) planks of cross section $32 \times 140 \mathrm{~mm}^{2}$ and labelled $C 18$ (NF-EN-338). Each plank was machined on four faces to a cross section of $24 \times 120 \mathrm{~mm}^{2}$ and cut to a length of $5 \mathrm{~m}$. The modulus of elasticity was then determined by the vibration method. Each plank was placed on two fixed supports separated by 4- $\mathrm{m}$ distance. An inductive accelerometer (HBM B12/500 model) was positioned

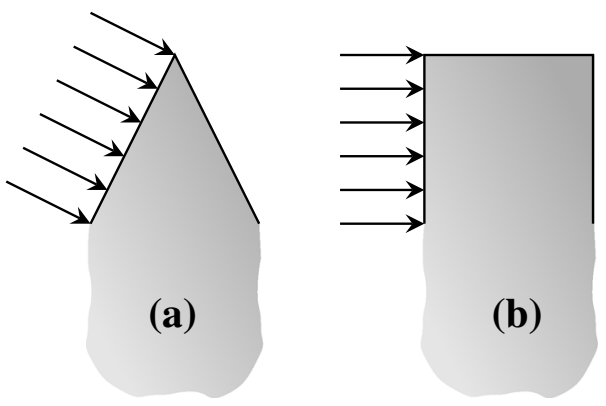

Fig. 2 Saw-tooth (a) and square-tooth (b) shapes; the principle of strength transmission

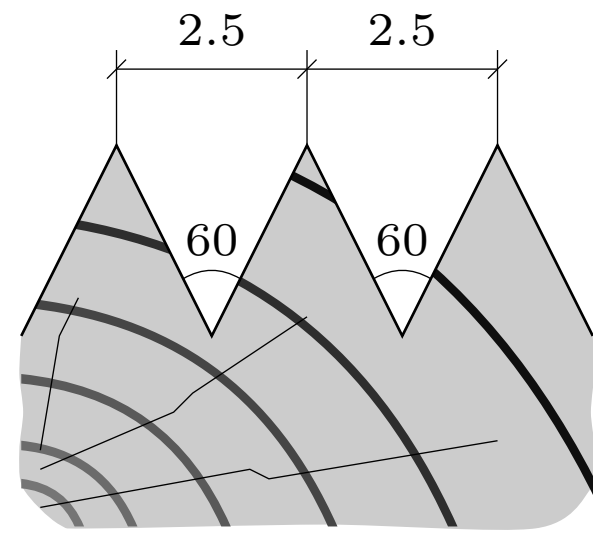

Fig. 3 Geometry of tooth grooves (2.5-mm step and $60^{\circ}$ tooth angle)

at mid-span to measure the initial natural frequency. Acceleration was measured by a data logger (HBM Spider 8 and Catman software version 4.5r3). After frequency analysis, the modulus of elasticity was obtained from Eq. 1, where shearing is neglected (Girard and Roy 2003).

$E=\frac{4 . f_{1}^{2} \cdot \ell^{4} \cdot m}{\pi^{2} \cdot I}$

With:

$E \quad$ : modulus of elasticity $\mathrm{MPa}$

$f_{1}:$ natural frequency $\mathrm{Hz}$

$\ell: \operatorname{span} \quad \mathrm{mm}$

$m: \quad$ linear density $\quad \mathrm{kg} \mathrm{m}^{-1}$

$I \quad: \quad$ inertia $\mathrm{mm}^{4}$

Each plank was grooved in the grain direction and then machined to a width of $8 \mathrm{~mm}$ and cut to a length of 100 $\mathrm{mm}$. Each element was weighted and paired off from different planks, so the test specimens of the connection came from different original lamellae. The moisture content was measured for each test specimen on the opposite face of the joint.

The mass and volume of the wood sample were corrected for an equivalent humidity of $12 \%$. Table 1 shows 
Table 1 Modulus of elasticity and density of the two elements composing the test piece

\begin{tabular}{|c|c|c|c|c|c|c|}
\hline \multirow[t]{2}{*}{ Piece } & \multicolumn{3}{|c|}{ Density $\left(\mathrm{kg} \mathrm{m}^{-3}\right)$} & \multicolumn{3}{|c|}{$\operatorname{MoE}(\mathrm{MPa})$} \\
\hline & $\rho_{e 1}$ & $\rho_{e 2}$ & $\rho_{\text {mean }}$ & $E_{e 1}$ & $E_{e 2}$ & $E_{\text {mean }}$ \\
\hline 1 & 422.0 & 423.4 & 422.7 & 11,139 & 11,691 & 11,415 \\
\hline 2 & 465.8 & 472.7 & 469.3 & 11,139 & 12,054 & 11,597 \\
\hline 3 & 427.0 & 428.6 & 427.8 & 11,139 & 12,054 & 11,597 \\
\hline 4 & 435.1 & 440.2 & 437.6 & 11,139 & 11,691 & 11,415 \\
\hline 5 & 430.5 & 430.6 & 430.5 & 11,139 & 12,054 & 11,597 \\
\hline 6 & 446.4 & 447.0 & 446.7 & 11,139 & 12,054 & 11,597 \\
\hline 7 & 464.4 & 464.7 & 464.5 & 8350 & 12,054 & 10,202 \\
\hline 8 & 477.3 & 482.1 & 479.7 & 8350 & 12,054 & 10,202 \\
\hline 9 & 453.0 & 457.5 & 455.2 & 8350 & 12,054 & 10,202 \\
\hline 10 & 494.4 & 515.0 & 504.7 & 8350 & 12,054 & 10,202 \\
\hline 11 & 541.2 & 543.1 & 542.2 & 11,691 & 12,054 & 11,873 \\
\hline 12 & 582.7 & 584.3 & 583.5 & 11,691 & 12,054 & 11,873 \\
\hline 13 & 530.0 & 531.4 & 530.7 & 11,691 & 12,054 & 11,873 \\
\hline 14 & 532.0 & 532.1 & 532.1 & 11,691 & 12,054 & 11,873 \\
\hline 15 & 550.3 & 563.6 & 557.0 & 11,691 & 12,054 & 11,873 \\
\hline 16 & 333.8 & 333.8 & 333.8 & 8350 & 11,633 & 9992 \\
\hline 17 & 325.0 & 325.2 & 325.1 & 8350 & 10,006 & 9178 \\
\hline 18 & 326.4 & 326.9 & 326.6 & 8350 & 10,006 & 9178 \\
\hline 19 & 337.6 & 337.6 & 337.6 & 8350 & 11,633 & 9992 \\
\hline 20 & 324.6 & 324.7 & 324.6 & 8350 & 10,006 & 9178 \\
\hline 21 & 337.4 & 337.5 & 337.5 & 11,691 & 11,633 & 11,662 \\
\hline 22 & 333.7 & 338.2 & 335.9 & 11,691 & 11,633 & 11,662 \\
\hline 23 & 324.2 & 327.9 & 326.1 & 11,139 & 11,633 & 11,386 \\
\hline 24 & 327.1 & 327.3 & 327.2 & 11,139 & 11,633 & 11,386 \\
\hline 25 & 305.2 & 306.3 & 305.8 & 11,139 & 10,006 & 10,573 \\
\hline 26 & 303.2 & 304.1 & 303.6 & 11,139 & 10,006 & 10,573 \\
\hline 27 & 324.5 & 324.5 & 324.5 & 8350 & 11,633 & 9992 \\
\hline 28 & 325.9 & 326.0 & 325.9 & 11,691 & 11,633 & 11,662 \\
\hline 29 & 320.9 & 323.8 & 322.3 & 11,691 & 10,006 & 10,848 \\
\hline 30 & 404.9 & 406.4 & 405.6 & 11,139 & 11,691 & 11,415 \\
\hline 31 & 393.2 & 394.8 & 394.0 & 11,139 & 11,691 & 11,415 \\
\hline 32 & 398.2 & 398.5 & 398.3 & 8350 & 11,691 & 10,020 \\
\hline 33 & 382.2 & 382.7 & 382.5 & 11,691 & 11,691 & 11,691 \\
\hline 34 & 396.0 & 396.0 & 396.0 & 11,691 & 11,691 & 11,691 \\
\hline 35 & 395.0 & 395.9 & 395.5 & 11,691 & 11,691 & 11,691 \\
\hline 36 & 392.2 & 397.4 & 394.8 & 11,691 & 11,691 & 11,691 \\
\hline
\end{tabular}

the density and modulus of elasticity obtained for each part of the test specimens. The measured average density of the specimens was $405.8 \mathrm{~kg} \mathrm{~m}^{-3}$ (COV 7.41\%). The measured modulus of elasticity of the specimens was $11,007 \mathrm{MPa}$ (COV 7.0\%). These values are higher than the mean density $\left(380 \mathrm{~kg} \mathrm{~m}^{-3}\right)$ and than the modulus of elasticity $(9000$ MPa) for solid wood $C 18$ according to NF EN 338.

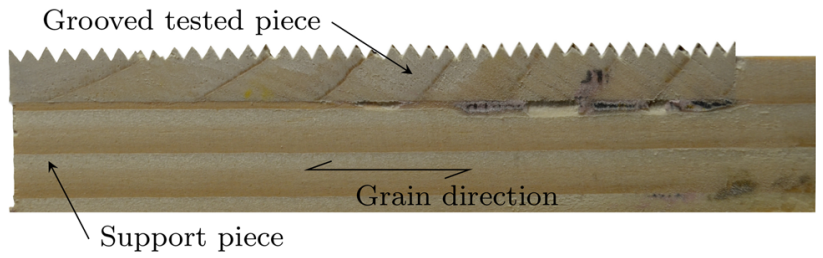

Fig. 4 Half test specimen side view

Finally, both grooved parts were each glued onto a support piece (Fig. 4) where the slope of the grain was in the load direction with the aim of measuring only the behaviour of the grooves.

The specimens were then stored in a climate-controlled room with $85 \%$ relative humidity and a temperature of $20^{\circ} \mathrm{C}$ for a week to obtain a humidity close to $12 \%$ for all specimens.

\subsection{Testing equipment}

The test principle proposed by Pirazzi (2005) was chosen to characterize interface shearing stiffness. This principle consists of a single plane of shearing. It limits friction forces between elements during assembly deformation which can occur during a double-plane shearing test. This principle produces boundary conditions close to those of multi-layer elements.

No scientific study has been published about test assemblies with pre-stressing holding contact. Therefore, a test assembly was designed to guarantee a homogeneous contact pressure at the interface of the test specimens. For that purpose, machining interfaces were placed between two lubricated steel plates and kept in contact by four calibrated springs; a load was then applied. This test assembly is presented in Fig. 5 and an example of a test is shown in Fig. 6. A test was done with a raw wood sample to check that the friction between the sample and the steel plate was negligible.

Test specimens were loaded by a testing machine (Instron) with a calibrated compression capacity of $100 \mathrm{kN}$. Tests were run under slip control. The deformation was measured in a videometric way with glued paper targets on the test specimens, which are visible in Fig. 6. These targets were monitored by a camcorder with a relative precision of $\pm 0.03 \mathrm{~mm}$.

Springs were gradually tightened to apply a specific pressure to maintain contact between the two parts of the test specimens. Each spring had a stiffness of 198.9 $\mathrm{N} \mathrm{mm}^{-1}$ (the value indicated by the manufacturer) and was checked by compression tests $\left(204.1 \mathrm{~N} \mathrm{~mm}^{-1} \pm 4.2\right)$ ) 


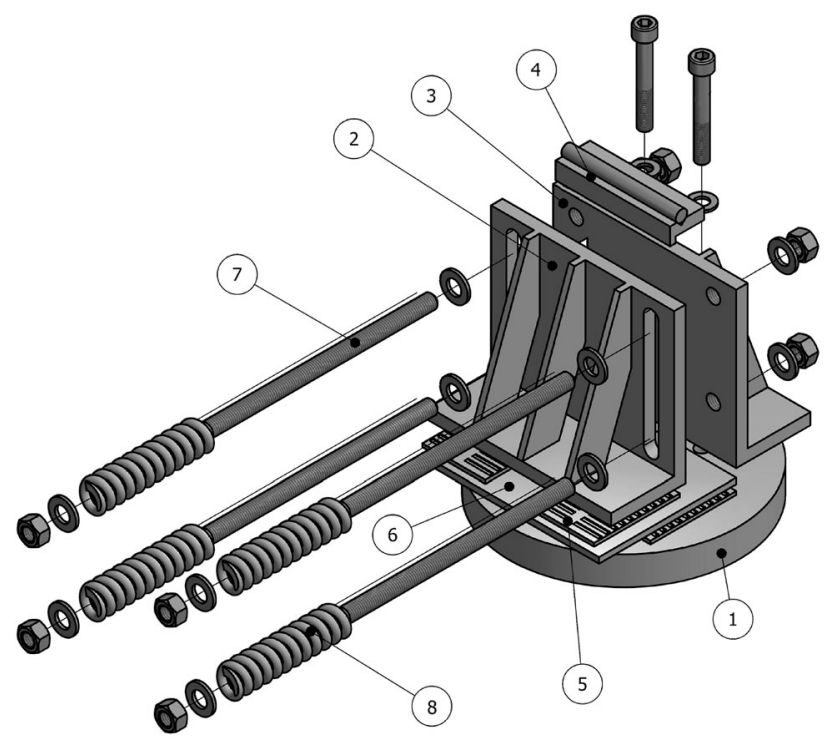

\begin{tabular}{l|l}
1 - Test assembly support & 5 - Needle roller cages \\
2 - Mobile bearing & 6 - Steel support of cages \\
3 - Fixed bearing & 7 - M12 threaded rod \\
4- Load steel support & 8 - Calibrated spring
\end{tabular}

Fig. 5 Test setup diagram

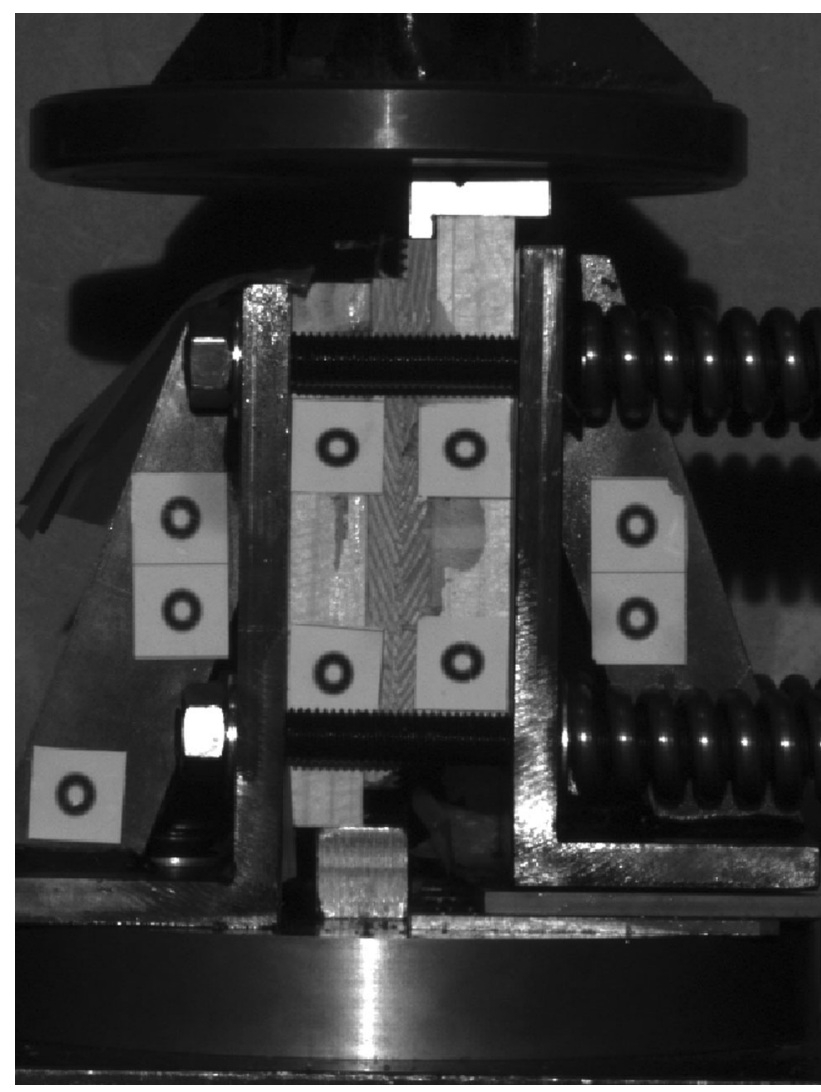

Fig. 6 Test setup and loading arrangement for shearing tests

\subsection{Shearing slip and stress in the specimen joint}

Test specimens were placed in the design test assembly with a contact surface of $100 \times 100 \mathrm{~mm}$. Three prestressing values were chosen to hold the test specimens: $0.14,0.28$, and $0.56 \mathrm{MPa}$. These three pre-stressing values were selected because they are related to common pressures in industrial pneumatic system (from 0.1 to $0.7 \mathrm{MPa}$ ).

Tests were intentionally stopped after $8 \mathrm{kN}$ of load for pre-stressing of 0.14 and $0.28 \mathrm{MPa}$ to avoid failure of the test specimens. This load value was determined from three previous tests for an estimated failure load of $12 \mathrm{kN}$. The last tests (pre-stressing of $0.56 \mathrm{MPa}$ ) were run until failure.

In order to compare the behaviour of grooves and glue joints, the standard elastic slip modulus for the shear connection $\left(k_{s}\right)$ was determined for each test specimen. The slip modulus was calculated according to EN 26891 based on the slope of the curve between 10 and $40 \%$ of the estimated failure load $F_{\text {est }}(12 \mathrm{kN})$.

\section{Results and discussion}

\subsection{Results}

The specific slip value is shown on each loadslip curve in Fig. 7 by the bold curve. The slip value is calculated as the mean of each slip value determined from behaviour between 10 and $40 \%$ of the estimated failure load. Test specimen behaviour is represented with dashed lines.

An overview of all the test results is presented in Table 2. For a pre-stress of $0.56 \mathrm{MPa}$, the failure load is chosen at the maximum load on each curve and the failure slip is chosen at the failure load. The mean failure stress was $1.58 \mathrm{MPa}(\mathrm{COV} 14.9 \%)$ as calculated from the surface in contact $(100 \times 100 \mathrm{~mm})$ and values from the load cell.

The mean curve for the $0.56 \mathrm{MPa}$ pre-stressing test series was obtained by discretising each curve by its slip to enable the calculation of an average (Fig. 8).

Mean values presented in Table 2 are calculated based on the individual load slip curve for each test specimen in the test series.

The average slip modulus per unit surface observed reached 1.47 (CoV 19.5\%), $1.87(\mathrm{CoV} 20.1 \%)$, and $2.30 \mathrm{~N} \mathrm{~mm}^{-3}(\mathrm{CoV} 18.6 \%)$ for $0.14,0.28$, and $0.56 \mathrm{MPa}$ pre-stresses, respectively.

\subsection{Discussion}

Every test specimen exhibits linear behaviour until a value of $0.56 \mathrm{~mm}$ is reached; then specimens reach a maximum load value in a non-linear way, and one of two cases 


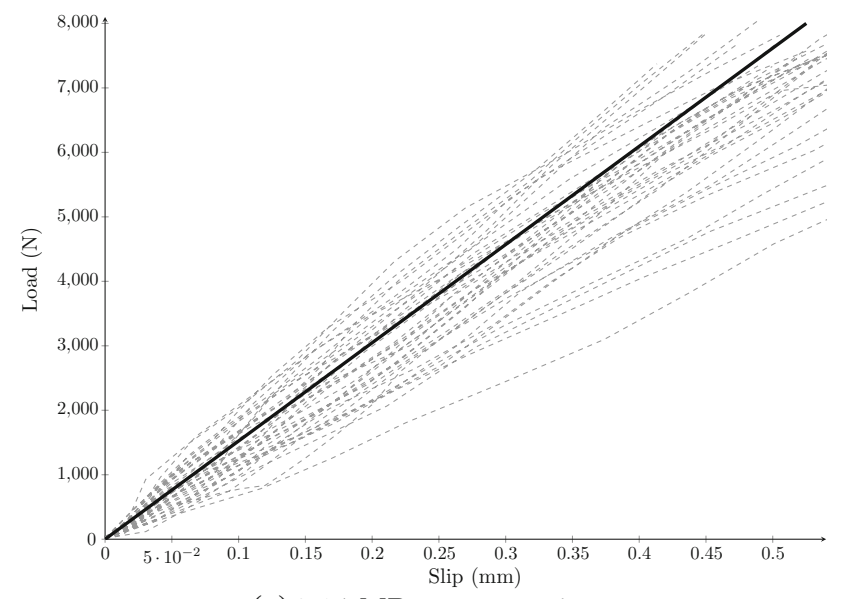

(a) $0.14 \mathrm{MPa}$ pre-stressing

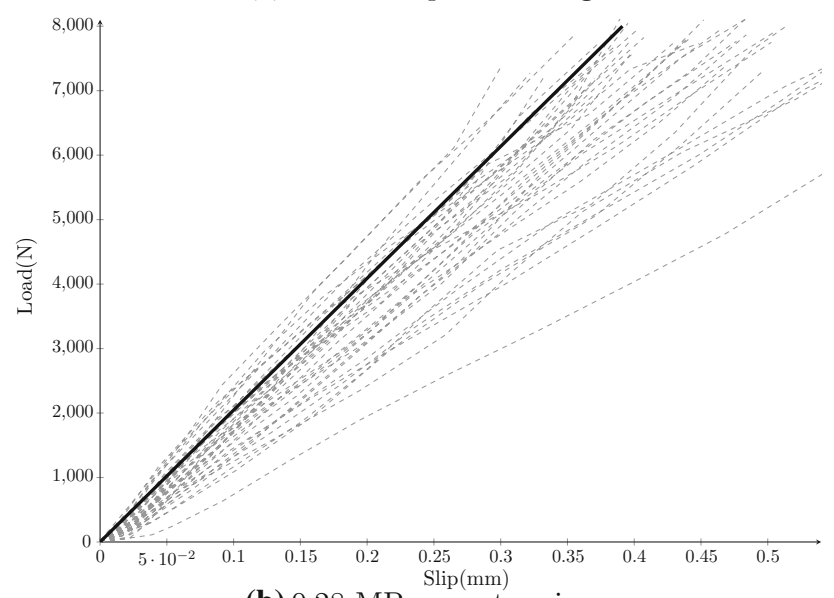

(b) $0.28 \mathrm{MPa}$ pre-stressing

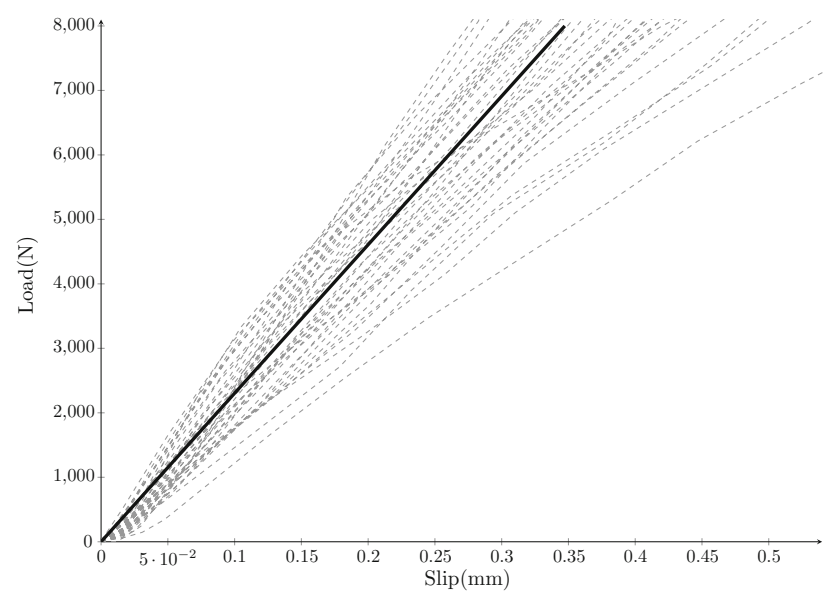

(c) $0.56 \mathrm{MPa}$ pre-stressing

Fig. 7 Relations between the load and slip of joints up to $8 \mathrm{kN}$

occurs. Some joints present loadslip curves with a relatively long quasi-ductile part with respect to their capacity (1.0 mm until failure) and others show more brittle behaviour (about $0.2 \mathrm{~mm}$ until failure). The post-peak behaviour is characterised by a slight gradual reduction of loadcarrying capacity until the end of the test.
Table 2 Shear stiffness $K$ in $\mathrm{N} \mathrm{mm}^{-3}$ for $0.14,0.28$, and $0.56 \mathrm{MPa}$ pre-stress, shear stress in MPa, and slip in $\mathrm{mm}$ at failure for a 0.56 MPa pre-stress

\begin{tabular}{|c|c|c|c|c|c|}
\hline \multirow[t]{2}{*}{ Pre-stressing } & \multicolumn{3}{|l|}{$K$} & \multirow{2}{*}{$\begin{array}{l}\tau_{\max } \\
0.56\end{array}$} & \multirow{2}{*}{$\begin{array}{l}\delta_{\max } \\
0.56\end{array}$} \\
\hline & 0.14 & 0.28 & 0.56 & & \\
\hline \multicolumn{6}{|l|}{ Piece } \\
\hline 1 & 1.32 & 1.60 & 2.10 & 1.73 & 1.11 \\
\hline 2 & 1.66 & 2.58 & 2.59 & 1.54 & 1.17 \\
\hline 3 & 1.04 & 1.45 & 1.60 & 1.70 & 1.21 \\
\hline 4 & 1.28 & 1.67 & 2.11 & 1.57 & 1.73 \\
\hline 5 & 1.24 & 1.26 & 1.58 & 1.37 & 0.63 \\
\hline 6 & 2.05 & 1.89 & 2.31 & 1.61 & 1.34 \\
\hline 7 & 1.08 & 1.57 & 1.70 & 1.69 & 0.76 \\
\hline 8 & 1.53 & 1.90 & 2.06 & 1.97 & 0.82 \\
\hline 9 & 1.24 & 1.71 & 2.18 & 1.53 & 0.78 \\
\hline 10 & 1.28 & 1.59 & 1.98 & 1.47 & 0.79 \\
\hline 11 & 1.59 & 1.98 & 2.38 & 1.83 & 1.36 \\
\hline 12 & 1.26 & 1.75 & 2.10 & 1.95 & 0.75 \\
\hline 13 & 1.44 & 2.22 & 2.14 & 2.12 & 0.85 \\
\hline 14 & 0.91 & 1.34 & 2.23 & 1.23 & 0.77 \\
\hline 15 & 1.53 & 2.02 & 2.45 & 1.77 & 0.65 \\
\hline 16 & 1.26 & 1.93 & 2.24 & 1.50 & 0.57 \\
\hline 17 & 1.24 & 2.12 & 2.79 & 1.54 & 0.77 \\
\hline 18 & 1.07 & 1.14 & 1.54 & 0.97 & 0.76 \\
\hline 19 & 2.05 & 2.86 & 2.83 & 1.67 & 0.60 \\
\hline 20 & 1.24 & 2.04 & 3.09 & 1.56 & 0.68 \\
\hline 21 & 1.65 & 2.23 & 2.35 & 1.68 & 0.62 \\
\hline 22 & 1.40 & 1.78 & 2.66 & 1.55 & 0.93 \\
\hline 23 & 1.56 & 2.08 & 2.55 & 1.50 & 1.18 \\
\hline 24 & 1.62 & 1.60 & 2.24 & 1.20 & 1.22 \\
\hline 25 & 1.73 & 1.73 & 2.49 & 1.72 & 1.50 \\
\hline 26 & 1.52 & 2.35 & 3.32 & 1.74 & 1.07 \\
\hline 27 & 1.74 & 2.04 & 2.94 & 1.00 & 1.18 \\
\hline 28 & 1.72 & 2.15 & 2.56 & 1.52 & 0.89 \\
\hline 29 & 1.71 & 1.77 & 2.47 & 1.54 & 0.97 \\
\hline 30 & 1.82 & 2.42 & 2.40 & 1.53 & 1.84 \\
\hline 31 & 2.01 & 1.50 & 1.81 & 1.58 & 1.25 \\
\hline 32 & 1.15 & 1.47 & 1.87 & 1.51 & 1.18 \\
\hline 33 & 1.68 & 1.89 & 2.06 & 1.56 & 1.35 \\
\hline 34 & 1.43 & 1.47 & 1.79 & 1.62 & 1.92 \\
\hline 35 & 1.24 & 2.06 & 2.76 & 1.79 & 1.72 \\
\hline 36 & 1.50 & 2.19 & 2.67 & 1.45 & 1.30 \\
\hline Mean & 1.47 & 1.87 & 2.30 & 1.58 & 1.06 \\
\hline STD & 0.29 & 0.38 & 0.43 & 0.23 & 0.37 \\
\hline $\operatorname{COV}(\%)$ & 19.5 & 20.1 & 18.6 & 14.9 & 34.8 \\
\hline
\end{tabular}

In all test series, failure of the grooves occurred at the base of some teeth (circles in Fig. 9); failures then gradually spread to others. Failures arise from rupture by transverse stress tension in raw material. The load-carrying 
Fig. 8 Relations between the load and slip of joints until failure for $0.56-\mathrm{MPa}$ prestressing
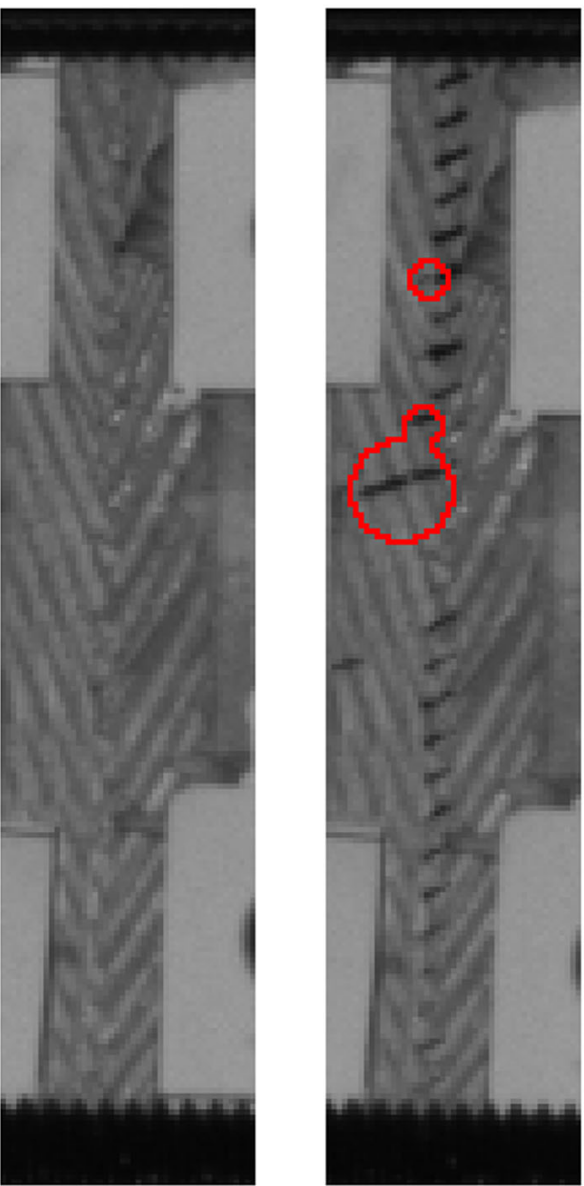

Fig. 9 Example test specimen before (left) and after (right) failure at the base of the teeth
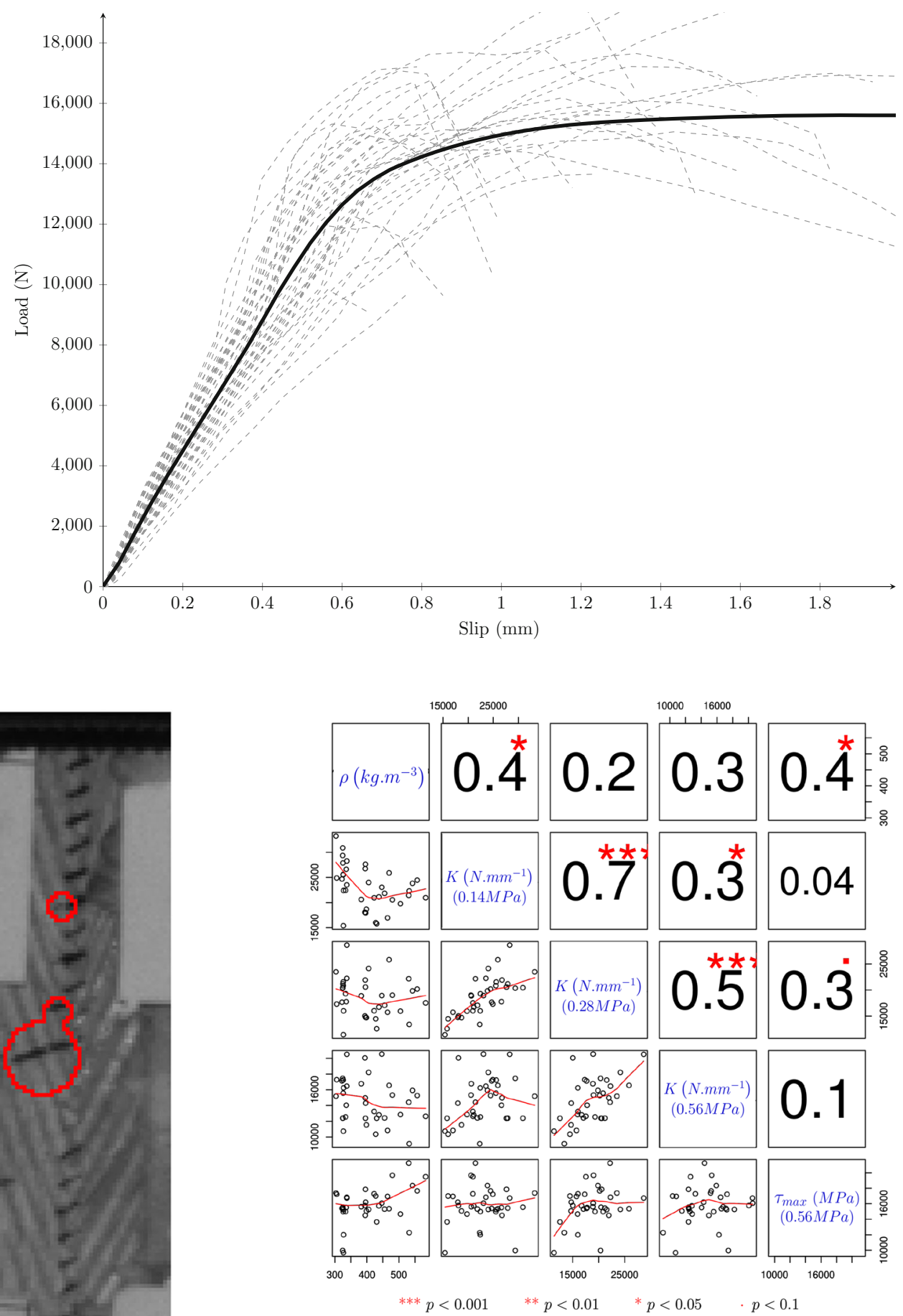

Fig. 10 Correlation matrix between density $\rho$, stiffness $K$, and failure stress $\tau_{\max }$

capacity decreases significantly as a failure appears at the base of a tooth.

The teeth bend as slip increases; this is an important point in understanding the behaviour of the assembly. Indeed, it is visible from observing the specimens during the tests that teeth generate the most displacement by their bending compared with raw material support. 
A matrix correlation (Fig. 10) was made with R software (R Development Core Team 2011) to highlight the dependency between each mechanical property of the specimens. The matrix correlation shows that a high stiffness does not induce a high failure stress, whatever the applied pre-stress. Failure stress seems to be caused by the density of specimens, which is consistent with literature (Hanhijarvi et al 2005; Simonaho and Silvennoinen 2006; Wang et al. 2008; Brännström et al. 2008; Viguier et al. 2014).

The results show that the grooved fasteners tested have a round load-carrying capacity (1.58 MPa) but a lower stiffness (from 1.47 to $2.30 \mathrm{~N} \mathrm{~mm}^{-3}$ ) compared to glue connection where the wood properties lead its behaviour. Indeed, adhesives have to be more resistant and more rigid than the support. In glued case, resistance comes from rolling shear and its mean value is $1.69 \mathrm{MPa}$ by considering a coefficient of variation of $15 \%$ for any strength class according to NF EN 14080. This standard gives the rolling shear modulus for glulam which is $65 \mathrm{MPa}$. A simplified way to compare grooved and glued stiffness is considering the test specimen as a raw beam which is blocked in deflection and rotation on one end and blocked in rotation on the other end where the load is applied.

The results show that the grooved fasteners tested had a similar load-carrying capacity (1.58 MPa), but a lower stiffness (from 1.47 to $2.30 \mathrm{~N} \mathrm{~mm}^{-3}$ ), compared to glue connections, where the wood's properties determined its behaviour. Indeed, adhesives must be more resistant and more rigid than the support. In the case of glued connections, resistance originates from rolling shear, and its mean value is $1.69 \mathrm{MPa}$, considering a coefficient of variation of $15 \%$, for any strength class according to NF EN 14080. So the grooved fasteners tested had a load-carrying capacity close to $95.8 \%$ of glued connections. This standard gives the rolling shear modulus for glulam, which is $65 \mathrm{MPa}$. A simplified way to compare grooved and glued stiffness is to consider the test specimen as a raw beam which is blocked in deflection and rotation on one end and blocked in rotation on the other end where the load is applied. Based on the mechanics of materials, the deflection at the end of this type of beam is deduced from Eq. 2 below:

$f=\frac{F L^{3}}{12 E I}+\frac{F L}{G S}$

With:

$\begin{array}{ccc}f & \text { Deflection } & \mathrm{mm} \\ F & \text { Load } & \mathrm{N} \\ L & \text { Length } & \mathrm{mm} \\ E & \text { Modulus of elasticity } & \mathrm{MPa} \\ G & \text { Shear modulus } & \mathrm{MPa} \\ I & \text { Moment of inertia } & \mathrm{mm}^{4} \\ S_{e f} & \text { Effective cross section } & \mathrm{mm}^{2}\end{array}$

Equation 2 includes shearing deflection, which is dominant for short beams. The diffusion effect is not taken into account in the calculation. The calculation values are as follows: $L=13.8 \mathrm{~mm}, E=300 \mathrm{MPa}, G=65 \mathrm{MPa}$, $I=8.3 \times 10^{6} \mathrm{~mm}^{3}$ and $S_{e f}=5 / 6 S=8333 \mathrm{~mm}^{2}$ (rectangular cross section). In this way, a deflection of $0.204 \mathrm{~mm}$ is obtained under a load of $8 \mathrm{kN}$ with a shear stiffness of $3.91 \mathrm{~N} \mathrm{~mm}^{-3}$.

Grooved connections are then comparable to glued connections. Grooved average resistance is approximately the same as for glued connections, which is explained by the fact that teeth transmit load both by compression and shear.

Grooved connections have a slip stiffness accounting for 38 to $59 \%$ of a glued connection's performance; this is due to the bending effect at the tooth level. Slip seems to be low, but would be sufficient for multilayer elements; indeed, it is common to use metallic fasteners (Johansen 1949; Tomasi et al. 2010; Chen and Lam 2013) for assembling layers. Four screws (6-mm diameter) have a slip stiffness of $7.7 \mathrm{kN} \mathrm{mm}^{-1}$ according to NF EN 1995-1, or $0.77 \mathrm{~N} \mathrm{~mm}^{-3}$ (for a unit equivalent surface). Hence, grooved connections are able to replace fasteners.

The interface stiffness must be well known when its value is lower than that of the raw material; indeed this case becomes an issue in theory for partial interaction beams or plates (Heimeshoff 1987; Kreuzinger 1995; Fragiacomo 2005; Girhammar and Pan 2007; Girhammar 2009; Fragiacomo and Lukaszewska 2011).

Therefore, the parts of each test specimen can be modelled as two springs arranged in parallel to obtain an equivalent slip stiffness in multi-layer element interfaces. The stiffness is determined for a unit surface of connection by Eq. 3 below:

$$
\frac{1}{K_{e q}}=\frac{1}{K_{p 1}}+\frac{1}{K_{p 2}}
$$

With:

$$
\begin{array}{ccc}
K_{e q} & \text { Stiffness of the whole joint } & \mathrm{N} \mathrm{mm}^{-1} \\
K_{p 1} & \text { Stiffness of one part } & \mathrm{N} \mathrm{mm}^{-1} \\
K_{p 2} & \text { Stiffness of the other part } & \mathrm{N} \mathrm{mm}^{-1}
\end{array}
$$

From previous equation, the mean stiffness of one shear plan groove can be deduced by:

$$
K_{p}=2 \cdot K_{e q}
$$

On the assumption of linear evolution of behaviour on the basis of the width and length of the assembly, load-slip behaviour is determined for a unit surface of a grooved joint. The stiffness of one plane of unit surface for shearing is $2.93,3.74$, and $4.61 \mathrm{~N} \mathrm{~mm}^{-3}$, respectively, for 0.14 , 
0.28 , and $0.56 \mathrm{MPa}$ of pre-stressing for grooves of a $100 \times$ $100 \mathrm{~mm}$ contact surface. These values allow calculations for modelling the behaviour of grooves in their linear region; i.e. for deflection up to $0.56 \%$.

The test for normality of Shapiro and Wilk (1965), recommended for samples of less than 50 individuals, allows a value of $W=0.938$ higher than $W_{0.05}=0.935$ to be obtained. In this case, $p=0.045(<0.05)$. These values mean that the risk of having a non-normal distribution is higher than $5 \%$. Therefore, calculation rules for characteristic values according to Eurocode 0 Annex D (NF EN 1990) cannot be used to obtain the characteristic shear resistance of grooves.

\section{Conclusion}

Grooves may be used effectively as shear connectors for composite elements. Indeed, grooves significantly increase the slip modulus and load-carrying capacity despite the different nature of shear connectors. This is interesting from the point of view of minimising the amounts of connectors used in manufacturing composite products.

The use of this type of fastener may be advantageous in an automated production process and represents an alternative to glued or screwed shear connections for composite floor elements as described in the introduction. Grooved connections have a slip stiffness accounting for 38 to $59 \%$ and a load-carrying capacity close to $95.8 \%$ of a glued connection's performance. However, although these values are below the glued connections, grooved connections should have enough slip stiffness and load-carrying performance for application in timber hollow-box structures.

From the tests in this experiment, it was noted that failures were initiated at the tooth base level. Tests were conducted on one geometrical shape owing to the preponderance of literature on this type of connection.

It would be interesting to investigate other geometrical shapes to measure the influence of geometry on the results. This is especially true for tooth angle and height, but also for surface roughness, which may change the interface coefficient of friction and thus have a significant impact on force transmission.

A larger-scale test campaign must be performed to measure mechanical property influences on results, for example those of density or modulus of elasticity.

Fasteners must be added to hold grooved interfaces like screws or welded-through wood dowels in contact (Bocquet et al. 2007; Girardon et al. 2014). This paper presented a first step for grooved connections. The next step would be the choice and optimisation of fasteners in order to reach maximum load-carrying capacity at a higher slip value with an adapted pre-stress.
Tests have been conducted on spruce. It would be interesting to investigate results using other species (e.g. hardwood and softwood), enabling the use of local resources close to the manufacturing workshop in order to limit environmental impact.

\section{References}

Adalberth K, Almgren A, Holleris Petersen E (2001) Life-cycle assessment of four multi-family buildings. Int $\mathrm{J}$ Low Energy Sustain Build 2:1-21

Aye L, Ngo T, Crawford RH, Gammampila R, Mendis P (2012) Life cycle greenhouse gas emissions and energy analysis of prefabricated reusable building modules. Energy Build 47:159-168

Bocquet J-F, Pizzi A, Despres A, Mansouri HR, Resch L, Michel D, Letort F (2007) Wood joints and laminated wood beams assembled by mechanically-welded wood dowels. J Adhes Sci Technol 21(3-4):301-317

Brännström M, Manninen J, Oja J (2008) Predicting the strength of sawn wood by tracheid laser scattering. BioResources 3(2):437-451

Chen Y, Lam F (2013) Bending performance of box-based crosslaminated timber systems. J Struct Eng 139(12):04013006

Crocetti R, Gustafsson, PJ, Danielsson H, Emilsson A, Ormarsson S (2010) Experimental and numerical investigation on the shear strength of glulam. In: Proceedings of international council for research and innovation in building and construction, working commission W18 - Timber structures, CIB-W18, vol CIB-W18, Meeting forty-three

Dodoo A, Gustavsson L, Sathre R (2014) Lifecycle primary energy analysis of low-energy timber building systems for multi-storey residential buildings. Energy Build 81:84-97

Fragiacomo M (2005) A finite element model for long-term analysis of timber-concrete composite beams. Struct Eng Mech 20(2):173-190

Fragiacomo M, Lukaszewska E (2011) Development of prefabricated timber concrete composite floor systems. Proc Inst Civ Eng Struct Build 164(2):13

Girard A, Roy N (2003) Dynamique des structures industrielles (Structural Dynamics in Industry) (In French). Hermes Science Publications

Girardon S (2014) Mechanical performances of screwed timber connections, improvement by mechanical preparation of the interfaces: its application to structural member. $\mathrm{PhD}$ thesis, Université de Lorraine

Girardon S, Barthram C, Resch L, Bocquet J-F, Triboulot P (2014) Determination of shearing stiffness parameters to design multilayer spruce beams using welding-through wood dowels. Eur J Wood Prod 72(6):721-733

Girhammar UA (2009) A simplified analysis method for composite beams with interlayer slip. Int J Mech Sci 51(7):515-530

Girhammar UA, Pan DH (2007) Exact static analysis of partially composite beams and beam-columns. Int $\mathrm{J}$ Mech Sci 49(2):239-255

Hanhijarvi A, Ranta-Maunus A, Turk G (2005) Potential of strength grading of timber with combined measurement techniques Vtt Publications, p 568

Heimeshoff B (1987) On the calculation of composite beams with slip occurring in the joints. Holz Roh- Werkst 45:237-241

Johansen K (1949) Theory of timber connections. Int Assoc Bridge Struct Eng 9:249-262

Kawasaki T, Kawai S (2006) Thermal insulation properties of woodbased sandwich panel for use as structural insulated walls and floors. J Wood Sci 52(1):75-83 
Kermani A, Hairstans R (2006) Racking performance of structural insulated panels. J Struct Eng asce 132(11):1806-1812

Kreuzinger H (1995) Mechanically jointed beams and columns. Timber Eng STEP 1:1-8

Pirazzi C (2005) On the Calculation of screw-laminated timber rib shells. PhD thesis, ENAC, Lausanne

R Development Core Team (2011) R: A Language and Environment for Statistical Computing. R Foundation for Statistical Computing, Vienna

Resch L (2009) Development of local laminated wood construction element using welded-through dowels. PhD thesis, ENSTIB

Shapiro SS, Wilk MB (1965) An analysis of variance test for normality (complete samples). Biometrika 52(3-4):591-611

Simonaho S-P, Silvennoinen R (2006) Sensing of wood density by laser light scattering pattern and diffractive optical element based sensor. J Opt Technol 73(3):170-174
Tomasi R, Crosatti A, Piazza M (2010) Theoretical and experimental analysis of timber-to-timber joints connected with inclined screws. Constr Build Mater 24(9):1560-1571

Viguier J, Jehl A, Collet R, Bleron L, Meriaudeau F (2014) Improving strength grading of timber by grain angle measurement and mechanical modeling. Wood Mater Sci Eng (ahead-ofprint): $1-12$

Wang S-Y, Chen J-H, Tsai M-J, Lin C-J, Yang T-H (2008) Grading of softwood lumber using non-destructive techniques. J Mater Process Technol 208(1):149-158

Zarnani P, Quenneville P (2014) Wood load-carrying capacity of timber connections: an extended application for nails and screws, pp 167-179 